\title{
The Role of Hospital Medicine in Emergency Preparedness: A Framework for Hospitalist Leadership in Disaster Preparedness, Response, and Recovery
}

\author{
Jason Persoff, MD, SFHM, Doug Ornoff, MD, PhD², Charles Little, DO, FACEP³
}

'Department of Hospital Medicine, University of Colorado Hospital, Aurora, Colorado; ${ }^{2}$ Hospitalist Training Track, Internal Medicine Residency Training Program, University of Colorado Hospital, Aurora, Colorado; ${ }^{3}$ Medical Director for Emergency Preparedness at University of Colorado Hospital, Department of Emergency Medicine University of Colorado and Colorado School of Public Health, University of Colorado Hospital, Aurora, Colorado

Recent high-profile mass casualty events illustrate the unique challenges that such occurrences pose to normal hospital operations. These events create patient surges that overwhelm hospital resources, space, and staff. However, in most healthcare systems, hospitalists currently show no integration within emergency planning or incident response. This review aims to provide hospitalists with an overview of disaster management principles so that they can engage their hospitals' disaster management system with a working fluency in emergency management and the incident command system. This review also proposes a framework for hospitalist involvement in preparation, response, and coordination during periods of crisis. Journal of Hospital Medicine 2018;13:713-718. (C) 2018 Society of Hospital Medicine ecent events, domestically and globally, have highlighted the numerous complex challenges that disasters and mass casualty incidents ( $\mathrm{MCls}$ ) impose on hospitals. Mass casualty events result from natural phenomena (eg, hurricanes, tornadoes, and wildfires), accidents (eg, plane crashes, building collapses, and toxic waste spills), or man-made crises (eg, terrorism). ${ }^{1-4}$ These events feature the potential to cause an acute surge of patients, which can overwhelm available hospital resources and personnel. Mass effect incidents are sustained crises, which often occur due to loss of infrastructure, epidemic infectious diseases, or need for hospital evacuations, and can completely overtax local and regional resources, thus requiring federal and state coordination. ${ }^{5}$

Hospital disaster response plans have traditionally centered on responses by the emergency department (ED) and associated surgical services to mass trauma-type events, without commensurate involvement of other hospital departments in either incident management operations or the planning process for mass effect incidents. ${ }^{6,7}$ In particular, the role of hospitalists in the leadership structure of various hospital disaster command structures remains undefined. ${ }^{8}$ However, recent disasters suggest that hospitalist involvement will highly benefit hospital emergency preparedness. ${ }^{9}$ Hospitalists possess specialized expertise in patient triage and disposition; medical comanagement with surgical services; coordination of complex

*Address for correspondence: Jason Persoff, MD, SFHM, Assistant Professor, Department of Hospital Medicine, University of Colorado Hospital, Mail Stop F782, 12401 E 17th Ave, Aurora CO 80045, Telephone: 904-343-4325; Fax: 720848-4293; E-mail: Jason.persoff@ucdenver.edu

Received: April 3, 2018; Revised: June 6, 2018; Accepted: June 24, 2018

() 2018 Society of Hospital Medicine DOI 10.12788/jhm.3073 medical care (usually with continuous $24 / 7$ in-house coverage); integration with the full spectrum of affiliated services, such as case management or patient rehabilitation; and quality improvement research. ${ }^{10-12}$ At our institution, hospitalists are involved in the direct care of over $60 \%$ of the patients admitted across all medical and surgical services. Thus, we believe that hospitalists are uniquely qualified to offer leadership in disaster preparation, response, and recovery if integrated into hospitals' incident command architectures. For example, although numerous acute patient surges are due to trauma $\mathrm{MCls}$, hospitalists may nevertheless act as the primary care providers in disasters that are medical in nature or that require rapid hospital evacuation and patient transfer (Table 1).

Although truly large-scale disasters are uncommon, several recent incidents exemplify scenarios with remarkably extreme acute patient surges (defined as $>20 \%$ of normal patient volumes), which completely overwhelm a hospital's capacity to maintain normal operations and require response from all available medical personnel, ideally in a preplanned and organized manner. ${ }^{13}$ The Las Vegas shooting on October 1, 2017, for example, resulted in 546 trauma victims, inundating two local hospitals and one regional facility. ${ }^{14,15}$ In another case, the deadliest tornado in modern US history struck Joplin, Missouri on May 22, 2011, destroying one of the two hospitals in the city and leaving an estimated 1,371 people injured, many of whom were presented to the one remaining area hospital. ${ }^{16}$ One of our team members (J.P.), a storm chaser from out-of-town, reported to the remaining functioning hospital and oversaw an impromptu hospital unit that received patients from the damaged hospital, ultimately caring for approximately 40 patients with a combination of medical and surgical issues from presentation through eventual disposition or transfer to outlying hospitals. ${ }^{17}$ Such incidents illustrate that during trauma events, 
TABLE 1. Disaster Examples with Implications for Involvement of Hospitalists as Primary Providers.

\begin{tabular}{lll}
\hline Disaster Type & Example & Implications for Hospitalists as Leaders \\
\hline Epidemic Infectious Disease & Pandemic influenza & $\begin{array}{l}\text { Hospital throughput of patients to subacute rehabilitation facilities, outpatient clinics, } \\
\text { and decompression to other hospital services }\end{array}$ \\
\hline Special Pathogens & Emerging viral pathogen (eg, Ebola) & $\begin{array}{l}\text { Special quarantine procedures and care for patients with significant infections } \\
\text { in dedicated isolation units }\end{array}$ \\
\hline Terrorism & $\begin{array}{l}\text { Chemical or radiation exposure } \\
\text { Weaponized infective biologics }\end{array}$ & Specialized personnel and personal protective equipment (PPE) \\
\hline Compromise of Hospital Infrastructure & $\begin{array}{l}\text { Massive power loss, } \\
\text { IT or communications failures, or structural damage to the hospital }\end{array}$ & $\begin{array}{l}\text { Maintenance of normal patient care in system under duress; direct hospital evacuation } \\
\text { and patient transfer }\end{array}$ \\
\hline Natural Disaster Affecting Hospital & Extensive regional wildfire or earthquake & Rapid hospital evacuation and patient transfer or implementation of crisis standards of care \\
\hline
\end{tabular}

hospitalists play critical roles for continuity of care for hospitalized disaster victims.

Therefore, we propose a means for incorporating hospitalists into the coordinated hospital disaster response effort, first by providing hospitalists with an overview of disaster management principles to allow their engagement with hospitals' disaster management system with working fluency and second, by proposing a framework for hospitalist involvement in hospital emergency response. These recommendations stem from our experience and from similar recommendations from a number of evidence-based articles on intensive care medicine, disaster preparedness, and emergency medicine literature cited in this article. To our knowledge, no evidence-based literature discusses hospital medicine or internal medicine specific to emergency preparedness. We aim to change such condition with this article.

\section{KEY PRINCIPLES OF INCIDENT MANAGE- MENT AND PREPAREDNESS: A PRIMER FOR HOSPITALISTS}

Effective participation in disaster response and planning requires a basic understanding of the organizational structures for incident management. ${ }^{18,19}$ Overall disaster response within the United States is guided by the National Response Framework, a national-level strategy that directs coordination between military and civilian response efforts, the latter of which are structured by the National Incident Management System (NIMS). ${ }^{20}$ NIMS organizes emergency management across all government levels (federal, state, and local) and the private sector under a common operational language and command structure. Both systems grew out of analyses of the September 11, 2001 attacks and Hurricane Katrina, indicating the need for a wider systemic organization to response efforts. ${ }^{1}$ State-level efforts are designed to mobilize resources to assist in community-level operations. Incident management always falls to the local authorities. At this local level, discrete hospitals often take part in healthcare coalitions that act in conjunction with other health entities, local public health departments, and emergency medical services, forming a multiagency coordination system. ${ }^{5}$ This healthcare coalition (emergency support function \#8 health and medical), in support of emergency managers of city and county governments, forms the core of the medical response. One commonality to all emergency management is the concept of an "all-hazards" approach, which aims to develop a broad and flexible strategy for efficient management of nearly any type of incident. This "all-hazards" approach allows effective management through each of the four phases of incident management: preparation, response, recovery, and ongoing mitigation.

Direct supervision over incident management is achieved through an Incident Command System (ICS), a hierarchical organization of positions involved in response. The top supervisory structure of ICS (Incident Command and General Staff) is the same regardless of the locale in which it operates, allowing coherent interoperability with other agencies. Incidents of any size are managed with a scalable approach; subordinate ICS positions, which are tailored according to specific needs, can be activated as needed. Healthcare implementation of the ICS structure led to the development of the Hospital Incident Command System (HICS), which now serves as the national standard for hospital-based incident management and facilitates the capacity of individual hospitals to coordinate with other resources regionally and is a part of NIMS for emergency response (Figure 1). ${ }^{21}$ The success of HICS-led regulatory agencies (namely the Centers for Medicare and Medicaid Services and the Joint Commission) to require ICS/HICS in-hospital incident response plans. ${ }^{22}$ The most recent HICS (Version V) excludes physician involvement in the overall management chart. However, we demonstrate how the inherent flexibility in ICS can adapt to involve hospitalists. Although HICS serves as a backbone that requires institutionally specific modifications, other institutions, such as ours, commonly have entire branches or positions renamed, reapportioned, or created to fill their specific needs. Specialized training in ICS, NIMS, and other aspects of hospital emergency response is beyond the scope of this article but is available for free through the Department of Homeland Security and FEMA. ${ }^{23}$

Perhaps, the defining feature of ICS/HICS is its expandability, allowing the response efforts to be scaled and tailored in size, scope, and complexity of that of the incident. ${ }^{24}$ At the same time, the principles of span of control and unity of com- 


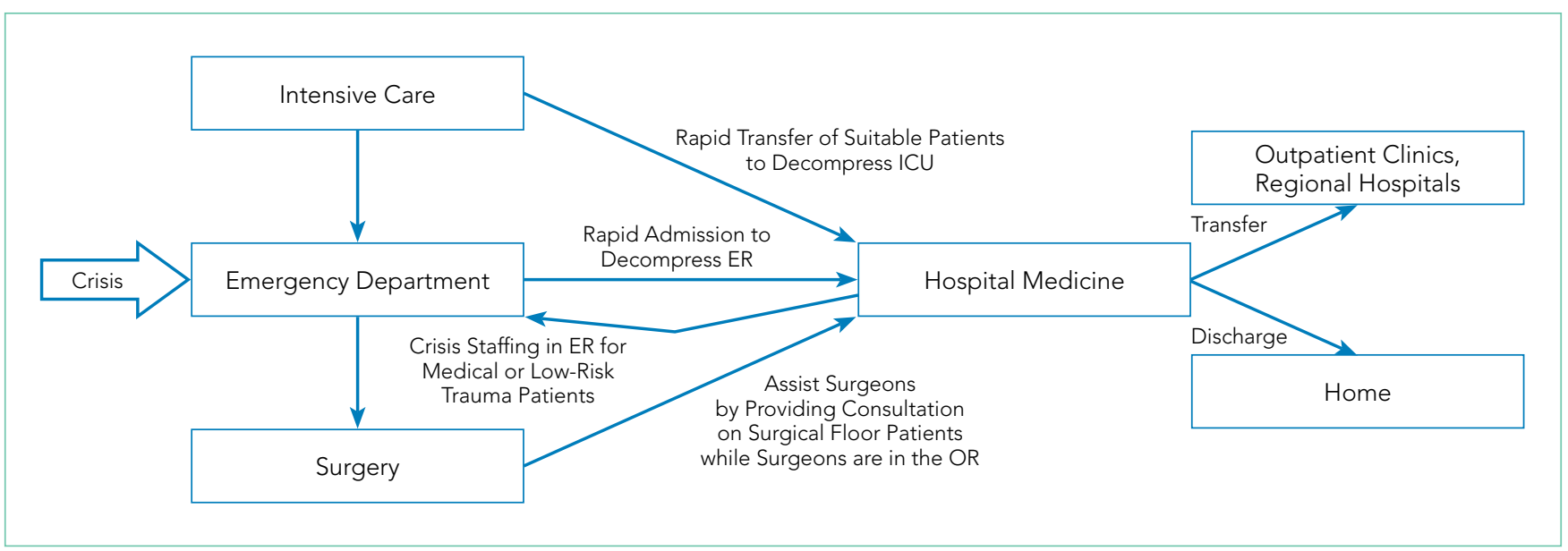

FIG 1. Hospital Medicine Master Flow.

Abbreviations: $E R$, emergency room; ICU, intensive care unit; OR, operating room.

mand promote efficient command structure by mandating each participant within the disaster response process to report to only one superior, whereas these superiors are limited to a manageable number of subordinates. For example, in Figure 2, all Strike Team Leaders report to the Hospitalist Unit Leader. Each strike team itself is comprised of approximately five similar assets (such as two physicians, two residents, and an advance practice provider).

\section{PROPOSED FRAMEWORK FOR HOSPITALIST INVOLVEMENT}

Although incidents vary in terms of their severity, acuity of onset, duration, and composition of patients, a defining feature of $\mathrm{MCl}$ is the rapid surge of patients with acute needs. Many
$\mathrm{MCl}$ are easily absorbed by local facilities. However, smaller hospitals or hospitals receiving patients from larger-scale incidents may become overwhelmed, in which larger incidents may result in an acute surge of over $20 \%$ of hospital capacity. ${ }^{13}$ Moreover, hospital surge capabilities have markedly diminished over the past decade due to overcrowding of emergency rooms, in part by admitted patients occupying the room space within the ED ("boarding"), further decreasing the hospitals' capacities to accept new patients. ${ }^{25}$

Our proposed framework for hospitalist involvement in $\mathrm{MCl}$ disaster response focuses on such a situation, with emphasis on augmentation of hospital surge capacity and facilitation of patient throughput and discharge. Notably, these goals are modified from the standard HICS architecture (Figures 1-2 and Table

TABLE 2. Summary of Targeted Hospitalist Goals during Hospital Incident Response

\begin{tabular}{|c|c|c|}
\hline Goal and Rationale & Strike Team & Patient Example \\
\hline $\begin{array}{l}\text { 1. Rapid intake of pending ER admits to medicine services } \\
\text { Rationale: free up ER bed space for incoming incident patients }\end{array}$ & Admissions and Internal Transfers In Strike Team & $\begin{array}{l}\text { 32-year-old male presented to ER before incident with probable } \\
\text { diabetic ketoacidosis, but full chemistry panel has not yet returned }\end{array}$ \\
\hline $\begin{array}{l}\text { 2. Rapid intake of incident patients requiring admission to medicine } \\
\text { services } \\
\text { Rationale: efficient intake of medicine admissions }\end{array}$ & Admissions and Internal Transfers In Strike Team & $\begin{array}{l}\text { 55-year-old male who developed a non-ST segment elevation } \\
\text { myocardial infarction while fleeing incident (no other injuries) }\end{array}$ \\
\hline $\begin{array}{l}\text { 3. Offload noncritically ill patients from acute-care services } \\
\text { Rationale: free up bed space and staff on acute-care services }\end{array}$ & $\begin{array}{l}\text { Surgical Comanagement and Consulting Strike Team } \\
\text { or Admissions and Internal Transfers In Strike Team }\end{array}$ & $\begin{array}{l}\text { 50-year-old female admitted to surgery } 3 \text { days prior to incident, now } \\
\text { on postoperative day number } 1 \text { after laparoscopic cholecystectomy } \\
\text { for gallstone-induced pancreatitis }\end{array}$ \\
\hline $\begin{array}{l}\text { 4. Provide consultative medical management for incident patients } \\
\text { on acute-care services } \\
\text { Rationale: assist in floor-level medical management of staff-limited } \\
\text { services }\end{array}$ & Surgical Comanagement and Consulting Strike Team & $\begin{array}{l}\text { 24-year-old female incident victim following rapid operative repair } \\
\text { of lacerated femoral artery due to a gunshot wound, previously in } \\
\text { hemorrhagic shock, now in need of continued fluid resuscitation } \\
\text { (supervise surgical intern managing patient) }\end{array}$ \\
\hline $\begin{array}{l}\text { 5. Coordinate rapid discharge of patients from general and specialty } \\
\text { medicine services } \\
\text { Rationale: free up hospital bed space }\end{array}$ & Discharges and Transfers Out Strike Team & $\begin{array}{l}62 \text {-year-old male admitted for elective cardiac stenting, } \\
\text { no postprocedure complication and may discharge immediately } \\
\text { to home }\end{array}$ \\
\hline $\begin{array}{l}\text { 6. Assist with minor trauma overflow } \\
\text { Rationale: assist acute-care services with triage management }\end{array}$ & Discharges and Transfers Out Strike Team & $\begin{array}{l}\text { 68-year-old female with ankle sprain sustained while fleeing incident } \\
\text { (otherwise medically stable) }\end{array}$ \\
\hline $\begin{array}{l}\text { 7. Ensuring current census of patients continue to receive medical care } \\
\text { Rationale: maintain standard of care }\end{array}$ & Continuity of Operations Strike Team & $\begin{array}{l}\text { 74-year-old male with community acquired pneumonia } \\
\text { on } 7 \mathrm{~L} \text { per minute of oxygen and hospital day number } 2\end{array}$ \\
\hline
\end{tabular}




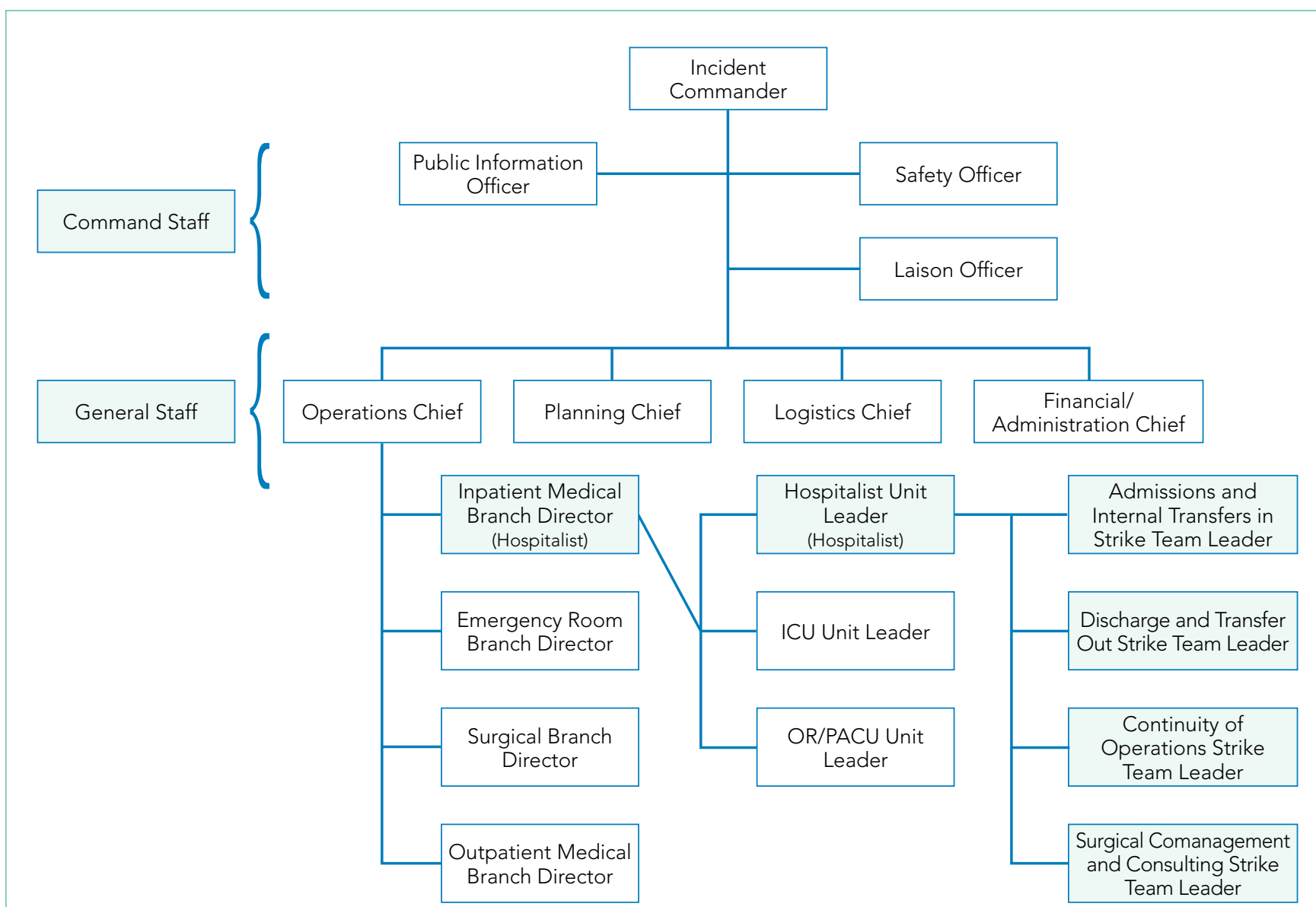

FIG 2. Incident Command Structure

Abbreviations: ICU, intensive care unit; OR, operating room; PACU, post-anesthesia care unit.

2). In this framework, hospitalists can play a critical role in decompressing the emergency room through admitting medical patients as rapidly as possible (even if preliminary workup is still pending), facilitating rapid discharge of patients to allow newer admissions to reach the floor, and prioritizing patients that could be transferred to other facilities or services and thus opening additional beds for admission (eg, accepting patients from the ICU or surgical floors to increase capacities on those services). Additionally, hospitalists can comanage surgical patients while surgeons are operating, assist intensivists with medical issues, and facilitate care of patients with minor injuries.

Using the HICS framework, each of those domains would be handled by a Strike Team led by one Team Leader whose goal is to operationalize various assets into a cohesive team specializing in those goals. Table 2 summarizes these goals, as presented in the context of patient examples.

To keep up with the ICS fundamentals, Hospitalist Unit Leaders may address a large $\mathrm{MCl}$ with all four strike teams or may only activate the strike teams needed for a less intensive $\mathrm{MCl}$. For example, a bombing may result in a patient surge of $30 \%$ more than normal operations and thus demand a full response that includes all the strike teams noted above. By contrast, a bus accident with 20 injured patients may only require a Hospitalist
Unit Leader to activate the "Admissions and Internal Transfers In" Strike Team to help offload a busy emergency room.

\section{HOSPITALIST LEADERSHIP IN HOSPITAL EMER- GENCY OPERATION PLAN DEVELOPMENT}

Emergency management is comprised of four phases: preparation, response, recovery, and mitigation. The latter two phases are beyond the scope of this paper. Although most of our review has focused on modeling disaster response, hospitalist leadership remains critical in preparing for disasters. A disaster often psychologically overwhelms care providers, who feel compelled to help but are uncertain where to begin. To aid the members of a disaster response team, a state-of-the-art hospitalist group creates Job Action Sheets (JASs) for each position in their HICS organizational chart; these sheets codify how to respond and what roles are needed. These formal, protocolized sheets provide individuals assigned to these positions a description of their roles and responsibilities, including to whom they report and over whom they supervise, and include detailed checklists to aid in reaching critical milestones during the response phase. For example, the "Surgical Comanagement and Consulting" Strike Team Leader JAS would likely include the expectations of surgeons for assisting in patient management (ie, auto-consult- 
ing on all postoperative patients) and whether nursing phone calls on surgical patients would be temporarily routed to the Strike Team during periods of OR surge.

Hospitalists are well suited as leaders in disaster preparation given their ability to coordinate care among a large spectrum of stakeholders. For example, case managers and social workers are essential members of a well-structured Discharge Strike Team. Their input is critical to ensure that disaster tactics - such as care coordination contracts with local skilled nursing facilities willing to expedite discharge in emergencies to their facilities - are in-place before a real $\mathrm{MCl}$. During Hurricane Sandy, mass evacuation of affected hospitals was effective through the Healthcare Facility Evacuation Center (a healthcare coalition of the New York Hospital Association) but nevertheless plagued with issues regarding situational awareness, poor communication between facilities, and difficulty bundling patients with medical records to receiving facilities - items which can be identified, anticipated, and thoroughly vetted by hospitalists well in advance of a real-world evacuation. ${ }^{26,27}$

As the Joint Commission mandates regular exercises of the emergency plan, protocols must be drilled regularly to uncover deficiencies and areas for improvement. ${ }^{18}$ The most common failure patterns in Emergency Operation Plans (EOPs) include unrealistic and ineffective expectations and poor communication between different personnel and groups, resulting in confusion and obfuscation. ${ }^{28-30}$ Therefore, EOPs need to be both comprehensive and realistic - characteristics that can only be tested through repeated drills. These characteristics can be tested during tabletop exercises, where hospitalists assume the role of a part of the ICS structure and with JAS in hand, attempt to reason how to respond to a given scenario. ${ }^{31}$ Our experience is that small-scale drills conducted more frequently than the bare minimum mandated by the Joint Commission are far more effective for success in real-life situations.

Although no hospital EOP can anticipate every contingency, hospitalists can proactively practice contingency planning for sustained system-wide mass effect incidents, in which hospitals are unable to maintain normal operations and shift from standard to crisis conventions of care. For example, mass effect incidents (ie, hospital damage from an earthquake or a massive and persistent regional power failure), require planning for how a hospital-wide mass evacuation would unfold and how efforts from multiple ancillary hospital services (engineering, nursing, security, and patient transport) would be integrated. As of 2015 , over $90 \%$ of hospitals have adopted an electronic health record, but only two-thirds of hospitals feature EOPs for information technology failures. ${ }^{32,33}$ Given the large footprint of hospitalists in clinical practice, HICS principles appear ripe for application in IT outages and through development of ICS positions structured specifically to this type of contingency. ${ }^{34}$

\section{CONCLUSION}

Disasters unfold rapidly with marked patient surges and the potential to strain healthcare systems over an extended period. However, in both instances, hospitalists are possibly some of the most qualified clinicians to prepare for and respond to such events. Hospitalists need to assume a leadership role in emergency preparedness to integrate seamlessly into hospital incident command structures and to shape the interdepartmental relationships vital to success - skills at which hospitalists excel. Although no plan can address all possible disasters, familiarity with HICS and well-prepared and well-written JASs should help groups respond and succeed in almost all hazards.

Disclosures: None of the authors have any conflicts of interest to report.

\section{References}

1. Homeland Security Presidential Directive-5. 2003.

2. Born CT, Briggs SM, Ciraulo DL, et al. Disasters and mass casualties: I. General principles of response and management. J Am Acad Orthop Surg. 2007;15(7):388-396. doi: 10.5435/00124635-200707000-00004

3. Born CT, Briggs SM, Ciraulo DL, et al. Disasters and mass casualties: II. explosive, biologic, chemical, and nuclear agents. J Am Acad Orthop Surg. 2007;15(8):461-473.

4. Christian MD, Hawryluck L, Wax RS, et al., Development of a triage protocol for critical care during an influenza pandemic. CMAJ. 2006;175(11):13771381. doi: 10.1503/cmaj.060911.

5. Barbera JA, Macintyre AG. Medical Surge Capacity and Capability: The Healthcare Coalition in Emergency Response and Recovery. In: Knebel A, Trabert E, eds. Department of Health and Human Services. 2007.

6. Roccaforte JD, Cushman JG. Disaster preparation and management for the intensive care unit. Curr Opin Crit Care. 2002;8(6):607-615.

7. Roccaforte JD, Cushman JG. Disaster preparedness, triage, and surge capacity for hospital definitive care areas: optimizing outcomes when demands exceed resources. Anesthesiol Clin. 2007;25(1):161-177, xi. doi: 10.1016/j.anclin.2007.01.002

8. Emergency Medical Services of California. Hospital Incident Command System V. 2014 [cited 2018 February 14th]. https://emsa.ca.gov/wp-content/uploads/ sites/47/2017/09/HICS_Guidebook_2014_11.pdf. Accessed June 1, 2018.

9. Sprung $C L$, Zimmerman JL, Christian MD, et al. Recommendations for intensive care unit and hospital preparations for an influenza epidemic or mass disaster: Summary report of the European Society of Intensive Care Medicine's Task Force for intensive care unit triage during an influenza epidemic or mass disaster. Intensive Care Med. 2010;36(3):428-443. doi: 10.1007/s00134010-1759-y.

10. Inpatient specialists help cut costs, reduce LOS. Hospitalists partner with case managers. Hosp Case Manag. 1997;5(5):79-81.

11. Thompson RE, Pfeifer K, Grant PJ, et al. Hospital medicine and perioperative care: A framework for high-quality, high-value collaborative care. J Hosp Med. 2017;12(4):277-282. doi: 10.12788/jhm.2717.

12. Gupta R, Moriates $C$, Harrison JD, et al. Development of a high-value care culture survey: A modified Delphi process and psychometric evaluation. BMJ Qual Saf. 2017;26(6):475-483. doi: 10.1136/bmjqs-2016-005612.

13. Tadmor B, McManus J, Koenig KL. The art and science of surge: Experience from Israel and the U.S. military. Acad Emerg Med. 2006;13(11):1130-1134. doi: 10.1197/j.aem.2006.06.043.

14. Myers AL. Vegas Hospitals Swamped With Victims After High-Rise Attack. Associated Press; 2017. https://www.msn.com/en-us/news/breakingnews/ vegas-hospitals-swamped-with-victims-after-high-rise-attack/ar-AAsQyZ8?ocid=HPCDHP. Las Vegas. Accessed June 1, 2018.

15. Craig T. As the Wounded Kept Coming, Las Vegas Hospitals Dealt With Injuries Rarely Seen in the US. In: Mello F, Sun L, eds. Washington Post: Washington Post; Oct 3, 2017.

16. Porth L. Preparedness and Partnerships: Lessons learned from the Missouri disasters of 2011. A Focus on Joplin. 2012, Missouri Hospital Association.

17. Persoff J. First Response Mode: May 22, 2011, Joplin Tornado. June 5, 2011 Available from: http://stormdoctor.blogspot.com/2011/06/first-responsemode-may-22-2011-joplin.html. Accessed Jun 1, 2018.

18. Dichter JR, Kanter RK, Dries D, et al. System-level planning, coordination, and communication: care of the critically ill and injured during pandemics and disasters: CHEST consensus statement. Chest. 2014;146(4 Suppl):e87S-e102S. doi: 10.1378/chest.14-0738.

19. Thomas TL, Hsu EB, Kim HK, Colli S, Arana G, Green GB. The incident command system in disasters: Evaluation methods for a hospital-based exercise. Prehosp Disaster Med. 2005;20(1):14-23. doi: 10.1017/S1049023X00002090.

20. FEMA. The Historical Contex of Emergency Management. [cited 2018 Feb- 
ruary 14th]; Available from: https://training.fema.gov/emi.aspx. Accessed June 1, 2018

21. Backer H. Hospital Incident Command System Guidebook 5th Edition. In Smiley D, Schoenthal L, eds. California Emergency Medical Services Authority, 2014. Accessed June 1, 2018.

22. Emergency Management Resources. Available from: https://www.jointcommission.org/emergency_management.aspx. Accessed June 1, 2018.

23. Incident Command System Training Program. Available from: https://training.fema.gov/emiweb/is/icsresource/trainingmaterials.htm.

24. Agency, F.E.M. NIMS and the Incident Command System. Nov 23, 2004; Available from: https://www.fema.gov/txt/nims/nims_ics_position_paper.txt. Accessed June 1, 2018.

25. Peleg K, Kellermann AL. Enhancing hospital surge capacity for mass casualty events. JAMA. 2009;302(5):565-567. doi: 10.1001/jama.2009.1119.

26. Adalja AA, Watson M, Bouri N, et al. Absorbing citywide patient surge during Hurricane Sandy: a case study in accommodating multiple hospital evacuations. Ann Emerg Med. 2014;64(1):66-73.e1. doi: 10.1016/j. annemergmed.2013.12.010.

27. Adalja AA, Watson M, Wollner S, Rambhia KJ, Toner ES. Response to the sudden closure of St. Vincent's Hospital: learning from a real, no-notice, prolonged surge event. Biosecur Bioterror. 2011;9(2):153-161. doi: 10.1089/ bsp.2011.0002.

28. Klein JS, Weigelt JA. Disaster management. Lessons learned. Surg Clin North Am. 1991;71(2):257-266

29. Frykberg ER. Medical management of disasters and mass casualties from terrorist bombings: How can we cope? J Trauma. 2002;53(2):201-212. doi: 10.1097/00005373-200208000-00001.

30. Lynn M, Gurr D, Memon A, Kaliff J. Management of conventional mass casualty incidents: Ten commandments for hospital planning. J Burn Care Res. 2006;27(5):649-658. doi: 10.1097/01.BCR.0000238119.29269.2B

31. Williams J, Nocera M, Casteel $C$. The effectiveness of disaster training for health care workers: A systematic review. Ann Emerg Med. 2008;52(3):21122, 222.e1-2. doi: 10.1016/j.annemergmed.2007.09.030.

32. Percent of Hospitals, By Type, that Possess Certified Health IT. 2015, US Department of Health and Human Services: Office of the National Coordinator for Health Information Technology.

33. Lee C, Robinson KM, Wendt K, Williamson D, et al. The preparedness of hospital Health Information Services for system failures due to internal disasters. Health Inf Manag. 2009;38(2):18-25. doi: 10.1177/183335830903800203.

34. Situations, C.o.G.f.E.C.S.o.C.f.U.i.D. and I.o. Medicine, Crisis Standards of Care: A Systems Framework for Catastrophic Disaster Response. Mar 21, 2012, Washington (DC): National Academies Press (US). 